

DOI: http://doi.org/10.48195/jie2021-184

\title{
ATIVIDADE EDUCATIVA SOBRE ESPIRITUALIDADE: RELATO DE EXPERIÊNCIA ${ }^{1}$
}

\section{Francisco Fernandes²; Frederico Bigolin Ferraz ${ }^{3}$; Rosiane Filipin Rangel ${ }^{4}$ \\ RESUMO}

Objetivou-se descrever a experiência de acadêmicos de enfermagem em uma atividade acerca da espiritualidade. A temática em questão trata-se de uma abordagem com enfoque na espiritualidade e religiosidade do ser humano, na sua singularidade e em suas crenças. Trata-se de um estudo descritivo cujas vivências foram teórico-práticas nas atividades da cadeira optativa, Espiritualidade e Saúde, da Universidade Franciscana. A atividade possibilitou aos acadêmicos conhecer acerca do Universalismo e entender a relação da espiritualidade com a saúde humana.

Palavras-chave: Espiritualidade; Enfermagem; Saúde; Integralidade do Cuidado

\begin{abstract}
The objective was to describe the experience of nursing students in an educational activity in which spirituality was discussed. The subject in question is an approach focusing on the spirituality and religiosity of the human being, on their uniqueness and on their beliefs. This is a descriptive study whose experiences were theoretical and practical in the activities of the optional chair, Spirituality and Health, at the Franciscan University. The activity made it possible for academics to know about Universalism and understand the relationship between spirituality and human health.
\end{abstract}

Key Words: Spirituality; Nursing; Health; Comprehensiveness of Care

\footnotetext{
${ }^{1}$ Relato de experiência desenvolvido na disciplina de Espiritualidade e Saúde, Curso de graduação em Enfermagem - Universidade Franciscana - UFN.

${ }^{2}$ Acadêmico de Enfermagem da UFN. E-mail: 01franciscofernandes@gmail.com

${ }^{3}$ Acadêmico de Enfermagem da UFN. E-mail: fredferraz14@gmail.com

${ }^{4}$ Orientadora. Doutora em Enfermagem. Docente da Universidade Franciscana - UFN. Docente da UFN. Email: rosiane@ufn.edu.br
} 


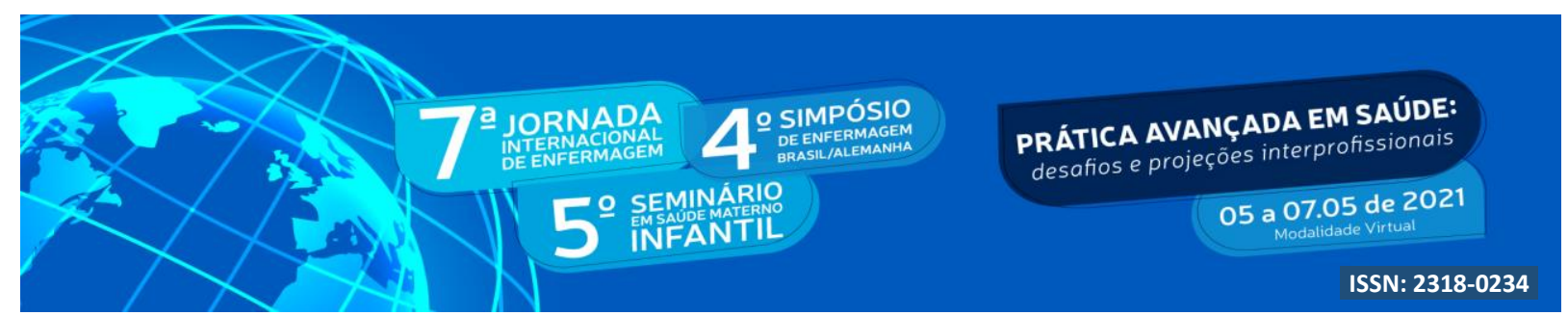

\section{INTRODUÇÃO}

Discutir acerca da religiosidade/espiritualidade direciona a compreender que as pessoas utilizam dessa temática, por vezes, como estratégia de enfrentamento importante diante de situações consideradas difíceis, como é o caso do diagnóstico de algumas patologias (FORNAZARI; FERREIRA, 2010).

As crenças espirituais/religiosas são parte importante da cultura, dos princípios e dos valores utilizados do ser humano (PERES, 2007). Muitas pessoas que passam por dificuldades, seja na vida pessoal e/ou profissional, acabam recorrendo as suas crenças, naquilo que lhe oferece conforto. Dessa maneira, relatam ter melhora, até mesmo cura de doenças e possíveis milagres, em todos os níveis sociais.

O avanço das ciências religiosas, na medida em que possibilitou a criação de conceitos e análises, que não se vinculam as tradicionais, ampliou as discussões, de uma forma que extrapola parcialmente as usuais e tensas competições entre os vários grupos religiosos (VASCONCELOS, 2009).

Nessa direção, cita-se o Universalismo. Esse é um construto fisiológico e espiritualteológico que advoga a ponto de umas ideias terem aplicabilidade universal. Uma comunidade que chama a si própria universalista pode enfatizar os princípios universais da maioria das religiões e aceitar outras religiões de uma forma inclusiva que considera a cultura europeia moderna, possibilitando a racionalização da fundamentação dos valores e, assim, gerando uma consciência moral descentrada ou universalista. (DANNER, 2016)

\section{OBJETIVO}

Descrever a experiência de acadêmicos de enfermagem em uma atividade educativa acerca da espiritualidade.

\section{METODOLOGIA}




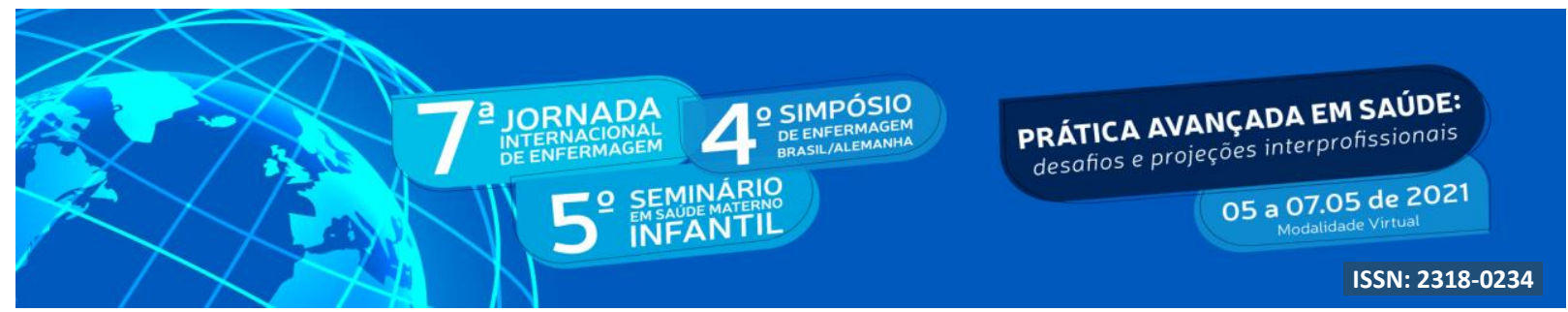

Trata-se de um estudo descritivo, do tipo relato de experiência, cujas vivências teóricas e práticas foram realizadas como atividade da disciplina optativa de Espiritualidade em Saúde, cursada no sétimo semestre do curso de Enfermagem, da Universidade Franciscana, no ano de 2019, sob orientação do professor responsável. Realizou-se atividades educativas em que se discutiu temáticas relacionadas a espiritualidade.

Para esse relato, descreve-se a atividade que teve a participação de um líder religioso que se denominou universalista. O grupo responsável pela proposta convidou um palestrante, que atua especificamente com o tema proposto, para esse momento, o encontro foi realizado em forma de roda de conversa, em que os alunos puderam contribuir, questionar e refletir sobre o tema apresentado.

\section{RESULTADOS E DISCUSSÃO}

No início do segundo semestre de 2019, foi proposto a divisão em grupos onde cada um selecionou um tema de sua preferência com relação a espiritualidade e saúde para serem apresentados em forma de seminário. A partir disso, o grupo decidiu a temática e convidou um líder religioso para participar do momento, com o intuito de agregar nas discussões possibilitadas na disciplina.

A atividade proposta teve como um dos objetivos mostrar os diferentes pontos de vista de diversas religiões e crenças e a relação com o bem-estar físico, mental, social e espiritual. Facilita-se, desta forma, o aprendizado dos alunos no instante em que ocorre a socialização dos conhecimentos proposta nessa discussão, por meio da ajuda mútua estabelecida no diálogo realizado (CALADO, 2019).

Se iniciou a discussão do tema com a solicitação da realização de uma roda para que ficasse mais fácil a visualização e interação dos colegas com o palestrante. Em seguida deu-se a apresentação do grupo responsável pelo tema e na sequência passou-se a palavra ao convidado.

O palestrante deu início a sua fala explicando os princípios e fundamentos da ideologia universalista, além de elucidar para os colegas como é a metodologia de trabalho. 


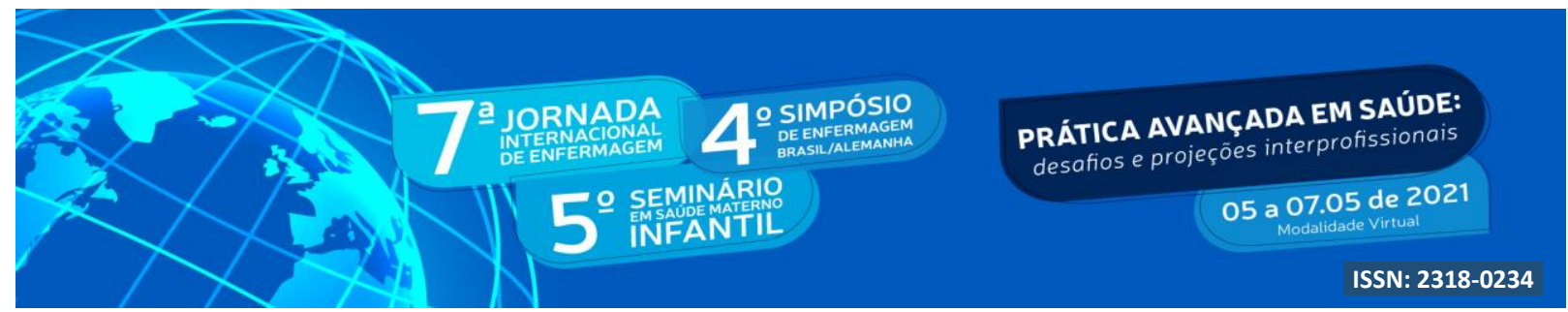

Exaltou-se também que essa crença é abrangente a todas as religiões, sem discriminação, unindo várias religiões.

Sobre o assunto em questão foi relatado os princípios do universalismo, onde os valores do ser humano são fundamentais para moldar o caráter da sociedade, assim sendo o materialismo irrelevante para a formação de pessoas de bem, garantindo uma qualidade de vida independentemente da classe social do indivíduo. (DANNER, et. al, 2019)

Nessa direção, com base nas discussões propostas, endente-se a importância da espiritualidade para o cuidado, visando a integralidade do ser humano. Os profissionais da saúde quando consideram a espiritualidade e religiosidade nas suas práticas, conseguem cuidar na singularidade e humanização. A enfermagem, por ser uma profissão que está em contato direto com o paciente, deve ter um olhar integral que contemple no seu cotidiano de cuidado todas as dimensões do ser (EVANGELISTA, 2016).

Observou-se, no decorrer da atividade, que os acadêmicos se envolveram na proposta e conseguiram sanar as dúvidas por meio dos questionamentos, bem como refletiram e conheceram sobre uma das crenças que fazem parte da cultura. Apesar de ser um tema pouco discutido na sociedade, alguns participantes tiveram dúvidas pertinentes ao assunto tratado, principalmente na questão das ideologias e/ou sua dinâmica.

\section{CONCLUSÃO}

A atividade possibilitou aos acadêmicos conhecer acerca do Universalismo e entender a relação da espiritualidade com a saúde humana. Evidenciou-se também a importância da disciplina para a formação dos profissionais de enfermagem, pois por estarem diretamente prestando o cuidado, precisam entender e considerar a multidimensionalidade humana. Considera-se, a importância dos temas abordados durante o semestre pela disciplina, pois esses mostram ao acadêmico a diversidade de crenças e religiões no mundo e como essas estão interligadas no processo de saúde e bem-estar do ser humano. 


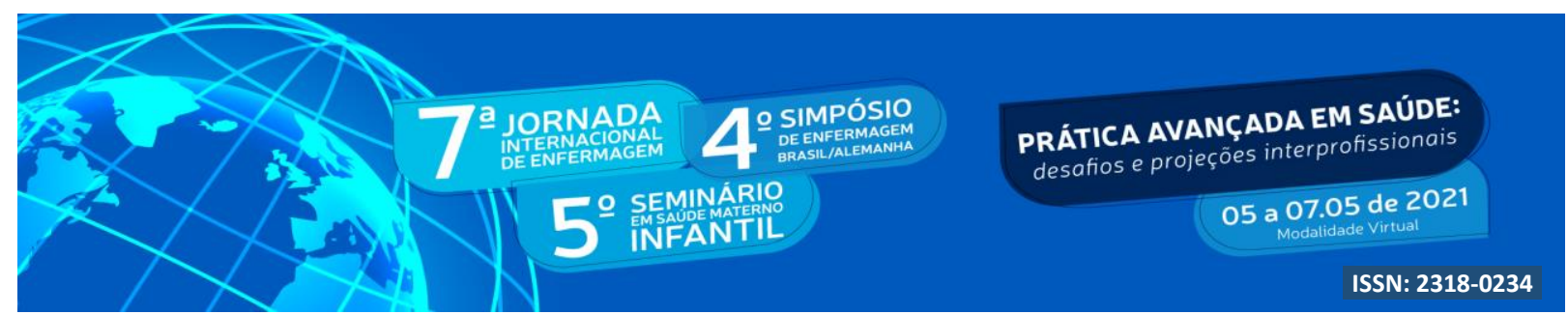

\section{REFERÊNCIAS}

DANNER, L. F.; BAVARESCO, A.; DANNER, F. Universalismo entre religiões e modernidade: a fundamentação do universalismo epistemológico-moral por meio da cooperação entre razão e religião. HORIZONTE - Revista de Estudos de Teologia e Ciências da Religião, v. 17, n. 52, p. 436-461, 30 abr. 2019.

DANNER, L. F. A crise das fundamentações universalistas: religiões universalistas e racionalismo ocidental em questão. Revista Interna de Filosofia - PUCRS, v. 7, n. 1, p. 3171, Abril. 2016

PERES, J. F. P; et al. Espiritualidade, religiosidade e psicoterapia. Revista Psiquiatra clínica. v. 34 n. 1 p. 136-145.2007.

VASCONCELOS, E. M. ESPIRITUALIDADE NA EDUCAÇÃO POPULAR EM SAÚDE. Cad. Cedes, Campinas, vol. 29, n. 79, P. 324, 2009.

FORNAZARI, S. A; FERREIRA, R. E. R. Religiosidade/Espiritualidade em Pacientes Oncológicos: Qualidade de Vida e Saúde. Psicologia: Teoria e Pesquisa, Vol. 26 n. 2, p. 265-272, Abr-Jun 2010.

CALADO, F.S.R et al. Ensino das Práticas Integrativas e Complementares na formação em Enfermagem. Revista de Enfermagem UFPE online. v. 13, n. 1, p. 261- 267, 2019.

EVANGELISTA, C. B; et al. Espiritualidade no cuidar de pacientes em cuidados paliativos: Um estudo com enfermeiros. Escola Anna Nery, p. 177, 2016. 